\title{
Cancer Statistics in Korea: Incidence, Mortality, Survival, and Prevalence in 2009
}

\author{
Kyu-Won Jung, MS ${ }^{1}$ \\ Sohee Park, PhD' \\ Hyun-Joo Kong, MS' \\ Young-Joo Won, PhD ${ }^{1}$ \\ Joo Young Lee, MD ${ }^{1}$ \\ Hong Gwan Seo, MD, PhD² \\ Jin-Soo Lee, MD, PhD ${ }^{1}$
}

\begin{abstract}
${ }^{1}$ The Korea Central Cancer Registry, Division of Cancer Registration and Surveillance, ${ }^{2}$ National Cancer Control Institute, National Cancer Center, Goyang, Korea
\end{abstract}

\section{Purpose}

This study overviews nationwide cancer statistics, including incidence, mortality, survival, and prevalence, and their trends in Korea based on 2009 cancer incidence data.

\section{Materials and Methods}

Incidence data from 1993-2009 were obtained from the Korea National Cancer Incidence Database, and vital status was followed through 31 December 2010. Mortality data from 1983-2009 were obtained from Statistics Korea. Crude rates and age-standardized rates for incidence, mortality, and prevalence; and relative survival were calculated.

\section{Results}

In total, 192,561 cancer cases and 69,780 cancer deaths were observed during 2009, and 808,503 10-year cancer prevalent cases occurred in Korea as of 1 January 2010. The incidence rate for all cancers combined showed an annual increase of 3.3\% from 1999 to 2009.

\section{Conclusion}

Stomach, liver and cervical cancers have been decreasing and thyroid, breast and colorectal cancers have been increasing at large. In particular, in 2009, colorectal cancer became the third most common cancer in females and for the first time ranked higher than stomach cancer, which had been the long-standing common cancer in Korea. While overall cancer incidence has been rapidly increasing in Korea, age-standardized cancer mortality rates have been declining since 2002, and cancer survival has been improving.

\section{Key words}

Incidence, Mortality, Survival, Prevalence, Neoplasms, Korea
The Korea Central Cancer Registry,

Division of Cancer Registration and Surveillance,

National Cancer Center, 323 Ilsan-ro,

Ilsandong-gu, Goyang 410-769, Korea

Tel: 82-31-920-2015

Fax: 82-31-920-2179

E-mail: shpark@ncc.re.kr

Received March 2, 2012

Accepted March 5, 2012

\section{Introduction}

Cancer has been the leading cause of death in Korea since 1983 [1] and has drawn much public health attention. More than 180,000 new cancer cases are diagnosed annually in Korea, and one of four deaths results from cancer [2,3]. This study provides an overview of the nationwide cancer statistics, including the incidence, mortality, prevalence, survival rates, and their trends in Korea.

\section{Data sources}

The Korean Ministry of Health and Welfare, initiated a nationwide hospital-based cancer registry called the Korea Central Cancer Registry (KCCR) as early as 1980 . The registry collected $80-90 \%$ of cancer cases annually from more than 180 training hospitals throughout the country. In 1999, the KCCR expanded cancer registration to cover the entire population under the Population-Based Regional Cancer Registry program. Details of the history, objectives, and activities of the KCCR have been documented [4]. Incidence data from 1999 to 2009 were obtained from 
the Korea National Cancer Incidence Database (KNCI DB). The completeness of incidence data for 2009 was $97.2 \%$, as determined by the Ajiki method [5].

Cancer cases were classified according to the International Classification of Diseases for Oncology, 3rd edition [6] and converted according to the International Classification of Diseases, 10th edition (ICD-10) [7]. The survival analysis used 1,804,388 cancer cases first diagnosed during 1993-2009 from the KNCI DB, and followed vital status through 31 December 2010.

Mortality data from 1983-2009 were obtained from Statistics Korea [1]. The cause of death was coded and classified according to the ICD10. Population data were also obtained from Statistics Korea using the resident registration population on July 1 of specified years.

\section{Analysis}

Crude rates (CRs) and age-specific rates of cancer incidence and mortality were calculated. Age-standardized rates (ASRs) were determined using the World Health Organization world standard population [8]. The cumulative risks of cancer incidence, which represent the probability of developing cancer during a lifetime, were also calculated. Changes in the annual ASRs of cancer incidence were examined by calculating the annual percentage change over a time period as $(\exp (b)-1) \times 100$, where $b$ is the slope of the regression of $\log$ ASR for a given calendar year [9].

Prevalence was also estimated to assess the level of cancer burden, which represents new and pre-existing cancer patients diagnosed during a given period of time who were still alive on an index date. Using the cancer incidence database from 2000-2009, we calculated the limited-duration prevalence, such as the 1-, 5-, and 10-year prevalence. For example, the 10-year prevalence was calculated from the number of people alive on 1 January 2010 who had been diagnosed with cancer within the previous 10 years. We applied the counting method using SEER*Stat software [10] to calculate the number of cases while adjusting for patients lost to follow-up [9].

The survival duration of each case was determined as the interval between the date of initial diagnosis and the date of death, date of loss to follow-up, or closing date for follow-up. Observed survival rates were calculated using the life table method and relative survival rates were examined with the Ederer II method [11] using an algorithm written in SAS by Dickman [12], with some minor modifications.

\section{Selected Findings}

\section{Incidence}

Table 1 presents the overall number of cancer incident cases, deaths, and prevalent cases during 2009 in Korea by sex and cancer site. In 2009 , 192,561 cancer incident cases and 69,780 deaths were observed in Korea. As of 1 January 2010, 808,503 10-year cancer prevalent cases were observed in Korea. The cumulative risk for developing cancer during a lifetime was $37.9 \%$ for men and $32.7 \%$ for women in 2009 .

Table 2 shows the cancer incidence rates by sex in 2009. The CRs of all sites combined in 2009 were 398.9 and 376.7 per 100,000 in males and females, respectively. The ASRs of all sites combined were 325.5 and 259.3 per 100,000 in males and females, respectively. In males, the five leading primary cancer sites were the stomach (CR, 80.2; ASR, 64.5), colon and rectum (CR, 60.6; ASR, 49.0), lung (CR, 56.4; ASR, 46.8), liver (CR, 47.9; ASR, 37.7), and prostate (CR, 29.6; ASR, 24.8), accounting for $68.8 \%$ of all newly diagnosed cancers in 2009 . In females, the most common cancer sites were the thyroid (CR, 108.2; ASR, 79.6), breast (CR, 54.1; ASR, 38.3), colon and rectum (CR, 40.0; ASR, 25.9), stomach (CR, 39.4; ASR, 25.5), lung (CR, 22.8; ASR, 13.9), and liver (CR, 16.2; ASR, 10.4), accounting for $74.6 \%$ of all newly diagnosed cancers. Thyroid cancer alone accounted for $28.7 \%(n=26,815)$ of incident cases in females in 2009.

\section{Mortality}

In total, 69,780 cancer deaths were reported in Korea during 2009, accounting for $28.3 \%$ of all deaths (Table 3). In 2009, the CRs of all sites combined were 176.3 and 104.7 per 100,000 for males and females, respectively. The ASRs of all sites combined were 146.7 and 62.9 per 100,000 for males and females, respectively. Cancers of the lung, liver, stomach, and colon and rectum were the most common fatal cancers, accounting for about $62.1 \%$ of all cancer deaths in 2009 (Table 4).

In males, the five leading fatal primary cancer sites in 2009 were the lung (CR, 43.8; ASR, 36.6), liver (CR, 33.9; ASR, 27.1), stomach (CR, 26.9; ASR, 22.3), colon and rectum (CR, 15.8; ASR, 13.2), and pancreas (CR, 9.0; ASR, 7.4). In females, lung cancer mortality (CR, 16.3; ASR, 9.2 ) increased gradually and was the most fatal cancer site in 2009 , followed by the stomach (CR, 13.9; ASR, 8.1), colon and rectum (CR, 12.6; ASR, 7.3), liver (CR, 11.4; ASR, 6.9), and breast (CR, 7.6; ASR, 5.2).

\section{Trends in cancer incidence}

Tables 5-7 present the cancer incidence rates during 1999-2009 in Korea for all sites combined and for selected cancer sites. The incidence rate for all sites combined increased by $3.3 \%$ annually $(1.6 \%$ in males, $5.3 \%$ in females) from 1999 to 2009 . The rapid increase in cancer incidence is also illustrated in Fig. 1.

As shown in Fig. 2, the incidence rates have continued to increase for colorectal and thyroid cancers in both sexes, along with breast cancer in females and prostate cancer in males. In contrast, the incidences of liver cancer in both sexes and cervical cancer in females have decreased. Stomach cancer incidence rates remained the same in males and females. One notable aspect was the sharp increase ( $25.1 \%$ annually) in the incidence of thyroid cancer in females. Improvements in the sensitivity of diagnostic 


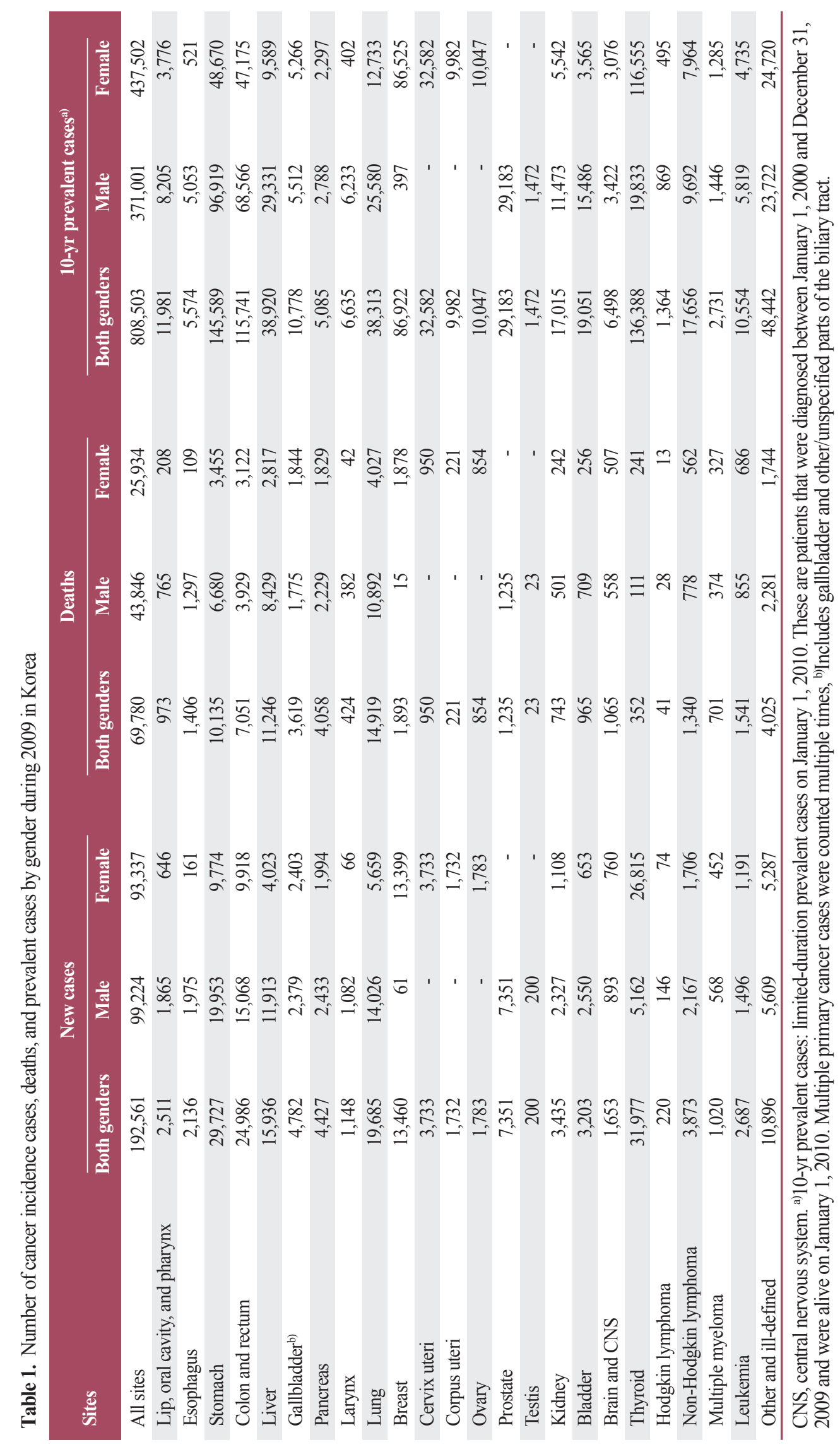


Table 2. Crude and age-standardized cancer incidence rates by gender during 2009 in Korea

\begin{tabular}{|c|c|c|c|c|c|c|}
\hline \multirow{2}{*}{ Sites } & \multicolumn{3}{|c|}{ Crude incidence rates $/ 100,000$} & \multicolumn{3}{|c|}{ Age-standardized incidence rates $/ 100,000^{\text {a) }}$} \\
\hline & Both genders & Male & Female & Both genders & Male & Female \\
\hline All sites & 387.8 & 398.9 & 376.7 & 282.0 & 325.5 & 259.3 \\
\hline Lip, oral cavity, and pharynx & 5.1 & 7.5 & 2.6 & 3.7 & 6.0 & 1.8 \\
\hline Esophagus & 4.3 & 7.9 & 0.6 & 3.1 & 6.5 & 0.4 \\
\hline Stomach & 59.9 & 80.2 & 39.4 & 43.0 & 64.5 & 25.5 \\
\hline Colon and rectum & 50.3 & 60.6 & 40.0 & 36.2 & 49.0 & 25.9 \\
\hline Liver & 32.1 & 47.9 & 16.2 & 23.2 & 37.7 & 10.4 \\
\hline Gallbladder ${ }^{\text {b) }}$ & 9.6 & 9.6 & 9.7 & 6.7 & 8.0 & 5.7 \\
\hline Pancreas & 8.9 & 9.8 & 8.0 & 6.2 & 8.0 & 4.8 \\
\hline Larynx & 2.3 & 4.3 & 0.3 & 1.7 & 3.6 & 0.2 \\
\hline Lung & 39.6 & 56.4 & 22.8 & 27.8 & 46.8 & 13.9 \\
\hline Breast & 27.1 & 0.2 & 54.1 & 19.4 & 0.2 & 38.3 \\
\hline Cervix uteri & 7.5 & - & 15.1 & 5.4 & - & 10.5 \\
\hline Corpus uteri & 3.5 & - & 7.0 & 2.6 & - & 5.0 \\
\hline Ovary & 3.6 & - & 7.2 & 2.7 & - & 5.2 \\
\hline Prostate & 14.8 & 29.6 & - & 10.4 & 24.8 & - \\
\hline Testis & 0.4 & 0.8 & - & 0.4 & 0.8 & - \\
\hline Kidney & 6.9 & 9.4 & 4.5 & 5.1 & 7.5 & 3.1 \\
\hline Bladder & 6.5 & 10.3 & 2.6 & 4.5 & 8.5 & 1.5 \\
\hline Brain and CNS & 3.3 & 3.6 & 3.1 & 2.9 & 3.4 & 2.5 \\
\hline Thyroid & 64.4 & 20.8 & 108.2 & 47.5 & 15.4 & 79.6 \\
\hline Hodgkin lymphoma & 0.4 & 0.6 & 0.3 & 0.4 & 0.5 & 0.3 \\
\hline Non-Hodgkin lymphoma & 7.8 & 8.7 & 6.9 & 6.0 & 7.3 & 5.0 \\
\hline Multiple myeloma & 2.1 & 2.3 & 1.8 & 1.5 & 1.9 & 1.2 \\
\hline Leukemia & 5.4 & 6.0 & 4.8 & 5.0 & 5.9 & 4.2 \\
\hline Other and ill-defined & 21.9 & 22.5 & 21.3 & 16.5 & 19.3 & 14.3 \\
\hline
\end{tabular}

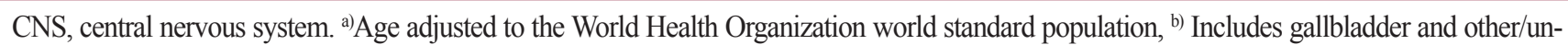
specified parts of the biliary tract.

Table 3. Ten leading causes of death during 2009 in Korea

\begin{tabular}{|c|c|c|c|c|}
\hline Rank & Cause of death & No. of deaths & Percent of all deaths & $\begin{array}{l}\text { Age-standardized } \\
\text { death rates } / 100,000^{\text {a) }}\end{array}$ \\
\hline & All causes & 246,942 & 100.0 & 349.5 \\
\hline 1 & Cancer & 69,780 & 28.3 & 97.8 \\
\hline 2 & Cerebrovascular disease & 25,838 & 10.5 & 34.2 \\
\hline 3 & Heart disease & 22,347 & 9.0 & 30.3 \\
\hline 4 & Intentional self harm (suicide) & 15,413 & 6.2 & 23.8 \\
\hline 5 & Diabetes mellitus & 9,757 & 4.0 & 13.1 \\
\hline 6 & Transport accidents & 7,147 & 2.9 & 11.5 \\
\hline 7 & Chronic lower respiratory diseases & 6,914 & 2.8 & 9.0 \\
\hline 8 & Disease of liver & 6,868 & 2.8 & 9.9 \\
\hline 9 & Pneumonia & 6,324 & 2.6 & 8.4 \\
\hline \multirow[t]{2}{*}{10} & Hypertensive diseases & 4,749 & 1.9 & 6.3 \\
\hline & Others & 71,805 & 29.1 & 105.3 \\
\hline
\end{tabular}

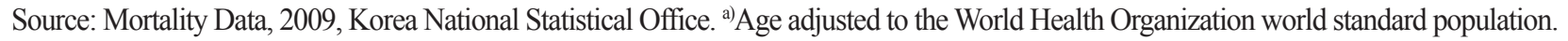


Table 4. Crude and age-standardized cancer mortality rates by gender during 2009 in Korea

\begin{tabular}{|c|c|c|c|c|c|c|}
\hline \multirow{2}{*}{ Sites } & \multicolumn{3}{|c|}{ Crude incidence rates $/ \mathbf{1 0 0 , 0 0 0}$} & \multicolumn{3}{|c|}{ Age-standardized incidence rates $/ 100,000^{\text {a) }}$} \\
\hline & Both genders & Male & Female & Both genders & Male & Female \\
\hline All sites & 140.5 & 176.3 & 104.7 & 97.8 & 146.7 & 62.9 \\
\hline Lip, oral cavity, and pharynx & 2.0 & 3.1 & 0.8 & 1.4 & 2.5 & 0.5 \\
\hline Esophagus & 2.8 & 5.2 & 0.4 & 2.0 & 4.3 & 0.2 \\
\hline Stomach & 20.4 & 26.9 & 13.9 & 14.0 & 22.3 & 8.1 \\
\hline Colon and rectum & 14.2 & 15.8 & 12.6 & 9.7 & 13.2 & 7.3 \\
\hline Liver & 22.6 & 33.9 & 11.4 & 16.2 & 27.1 & 6.9 \\
\hline Gallbladder ${ }^{\text {b) }}$ & 7.3 & 7.1 & 7.4 & 4.9 & 6.0 & 4.1 \\
\hline Pancreas & 8.2 & 9.0 & 7.4 & 5.6 & 7.4 & 4.2 \\
\hline Larynx & 0.9 & 1.5 & 0.2 & 0.6 & 1.3 & 0.1 \\
\hline Lung & 30.0 & 43.8 & 16.3 & 20.5 & 36.6 & 9.2 \\
\hline Breast & 3.8 & 0.1 & 7.6 & 2.7 & 0.1 & 5.2 \\
\hline Cervix uteri & 1.9 & - & 3.8 & 1.3 & - & 2.4 \\
\hline Corpus uteri & 0.4 & - & 0.9 & 0.3 & - & 0.6 \\
\hline Ovary & 1.7 & - & 3.4 & 1.2 & - & 2.3 \\
\hline Prostate & 2.5 & 5.0 & - & 1.6 & 4.6 & - \\
\hline Testis & 0.0 & 0.1 & - & 0.0 & 0.1 & - \\
\hline Kidney & 1.5 & 2.0 & 1.0 & 1.0 & 1.6 & 0.6 \\
\hline Bladder & 1.9 & 2.9 & 1.0 & 1.3 & 2.5 & 0.5 \\
\hline Brain and CNS & 2.1 & 2.2 & 2.0 & 1.7 & 1.9 & 1.5 \\
\hline Thyroid & 0.7 & 0.4 & 1.0 & 0.5 & 0.4 & 0.5 \\
\hline Hodgkin lymphoma & 0.1 & 0.1 & 0.1 & 0.1 & 0.1 & 0.0 \\
\hline Non-Hodgkin lymphoma & 2.7 & 3.1 & 2.3 & 1.9 & 2.6 & 1.4 \\
\hline Multiple myeloma & 1.4 & 1.5 & 1.3 & 1.0 & 1.2 & 0.8 \\
\hline Leukemia & 3.1 & 3.4 & 2.8 & 2.5 & 3.0 & 2.1 \\
\hline Other and ill-defined & 8.1 & 9.2 & 7.0 & 5.8 & 7.8 & 4.3 \\
\hline
\end{tabular}

CNS, central nervous system. a)Age adjusted to the World Health Organization world standard population, ${ }^{\text {b) }}$ Includes gallbladder and other/unspecified parts of the biliary tract.

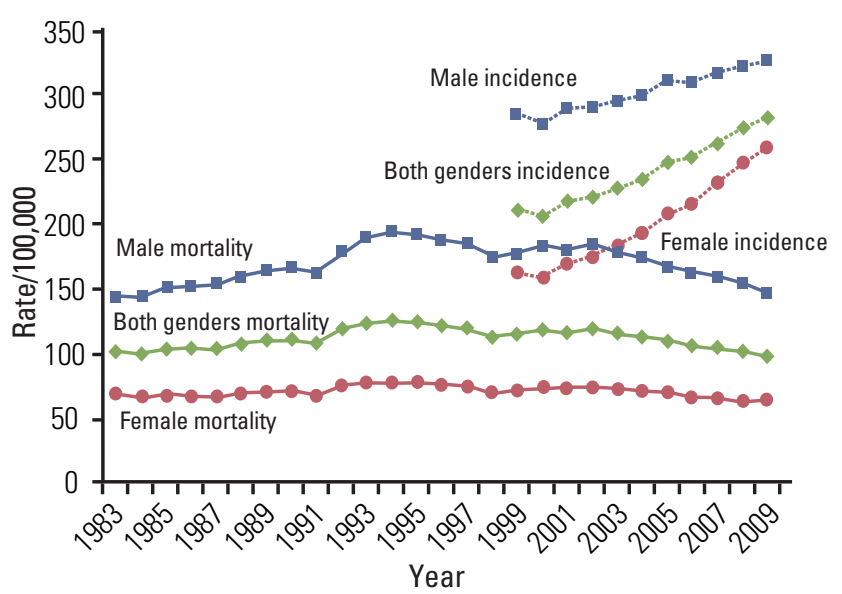

Fig. 1. Annual age-standardized cancer incidence and death rates for all sites by sex during 1983-2009 in Korea. Age standardization was based on the World Health Organization world standard population. techniques for thyroid cancer, such as the advent of ultrasound and fineneedle aspiration, have enabled the detection of subclinical disease. Therefore, the increased incidence of thyroid cancer may reflect the identification of previously undetected disease with these improved diagnostic techniques, rather than a true increase in the occurrence of thyroid cancer $[13,14]$. Furthermore, due to the construction of a 1999-2009 $\mathrm{KNCI} \mathrm{DB}$, the completeness of the Korea cancer registry data has improved gradually, and this may have contributed, in part, to the gradual overall increases in cancer incidence, particularly among elderly patients. In particular, in 2009, colorectal cancer became the third most common cancer in females and for the first time ranked higher than stomach cancer, which had been the long-standing common cancer in Korea.

\section{Age-specific incidence rates for selected cancer sites}

Table 8 presents the most common cancer sites by sex and age group in 2009. Leukemia and thyroid cancer were the most common forms in both sexes for ages 0-14 and 15-34 years, respectively. For males, stomach cancer was the most common in 35-64-year-olds, while lung cancer was 


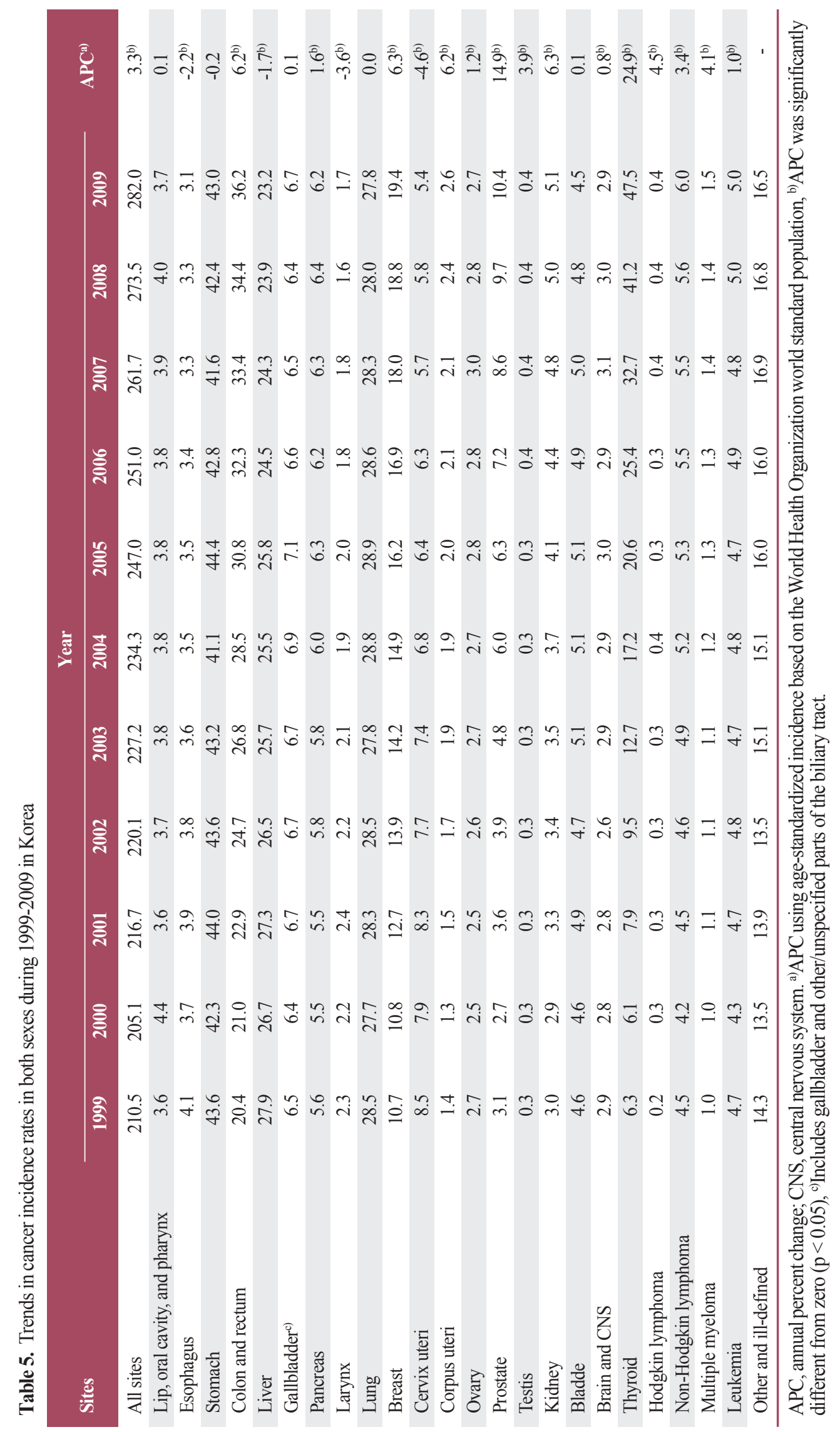




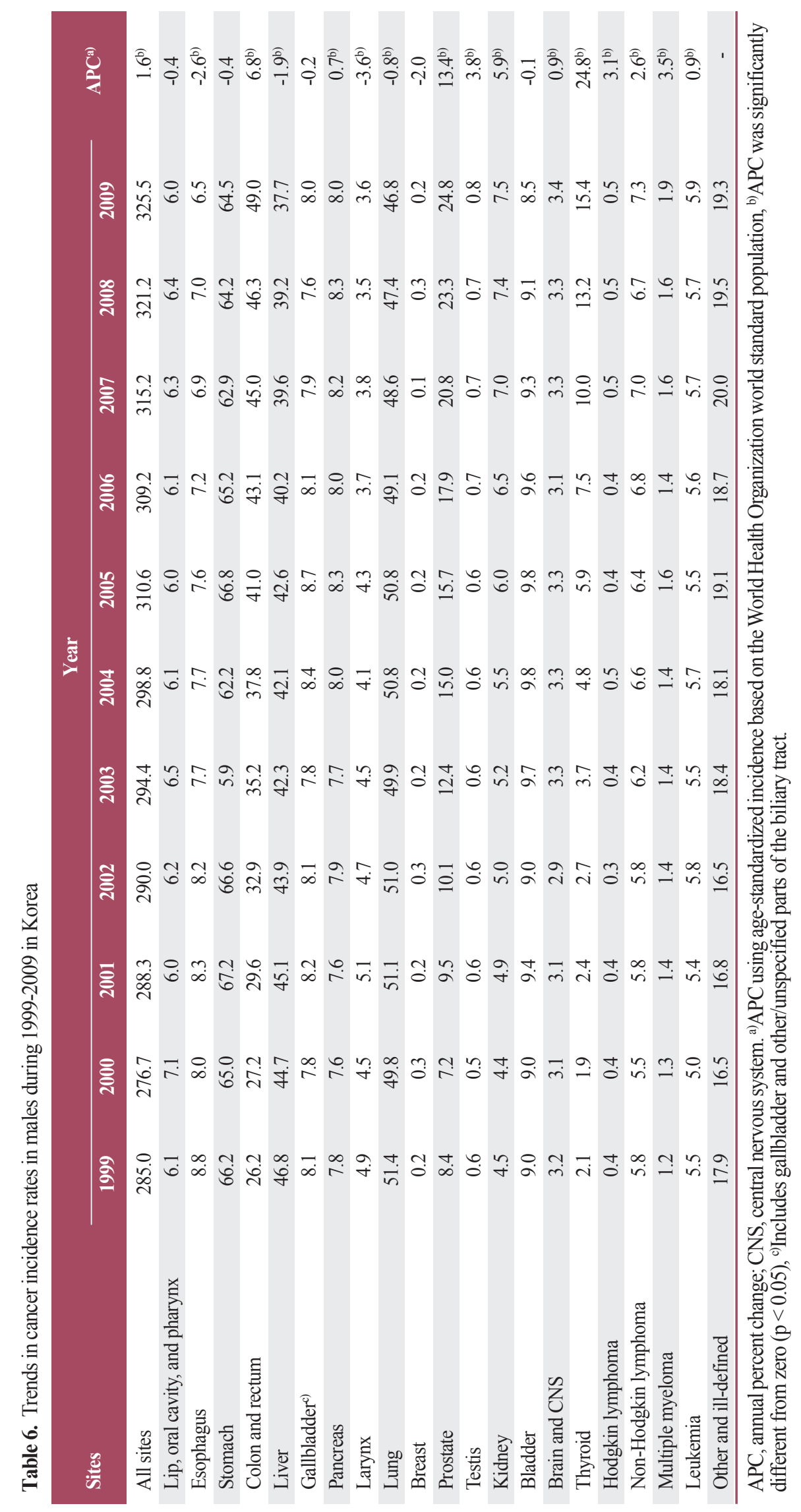




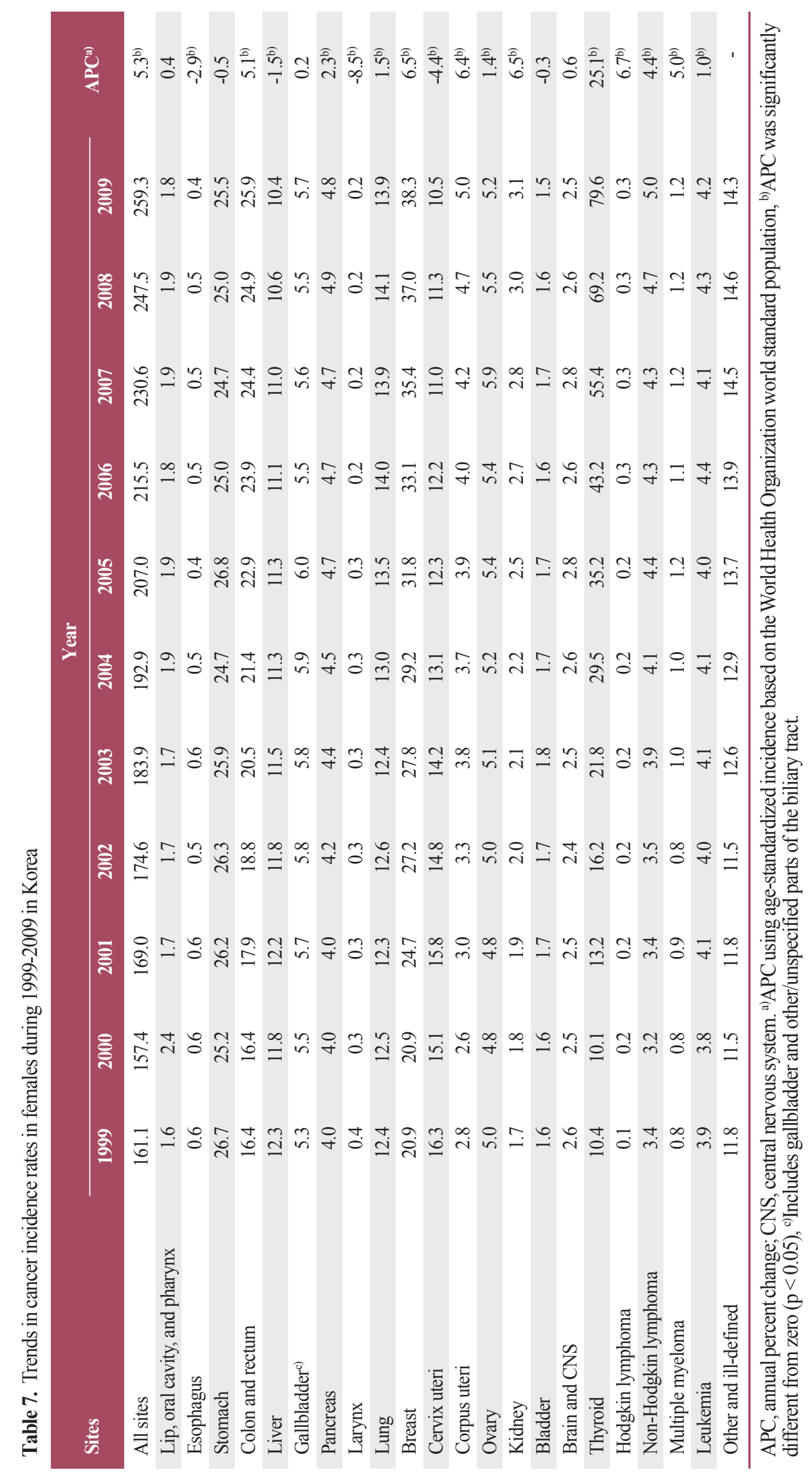



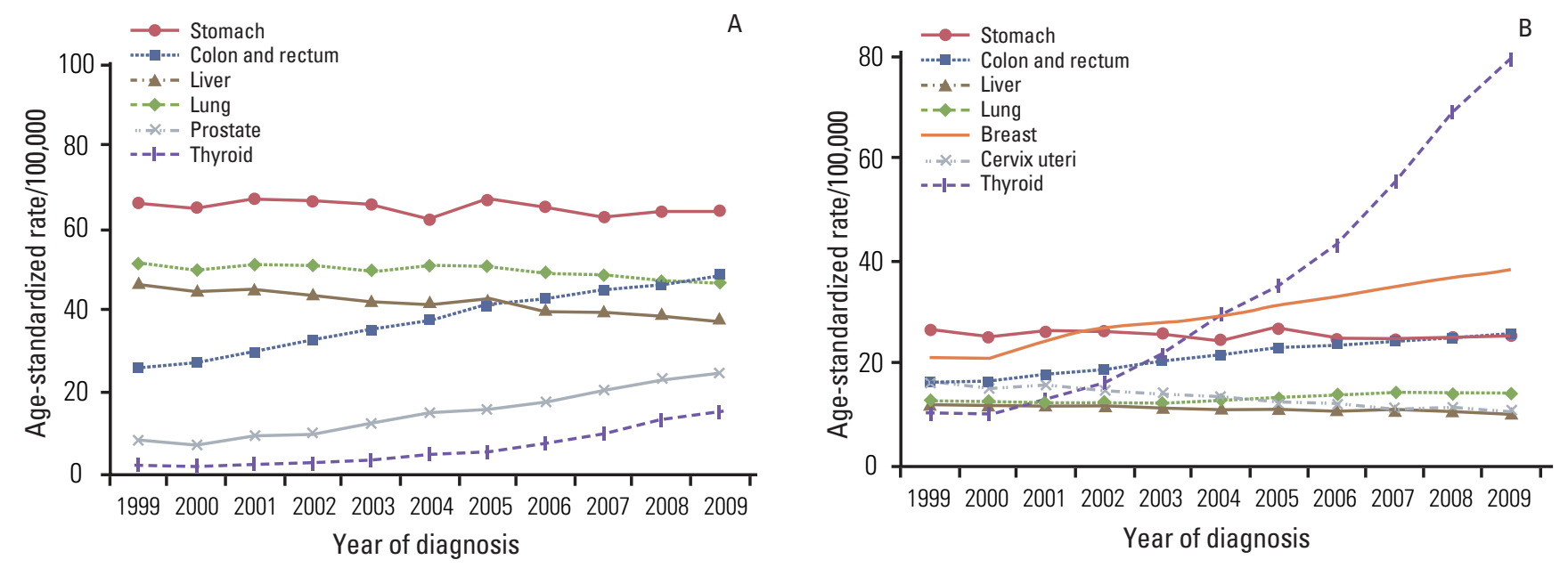

Fig. 2. Trends in age-standardized cancer incidence for selected cancers by sex during 1999-2009 in Korea. Age standardization was based on the World Health Organization world standard population. (A) Male. (B) Female.
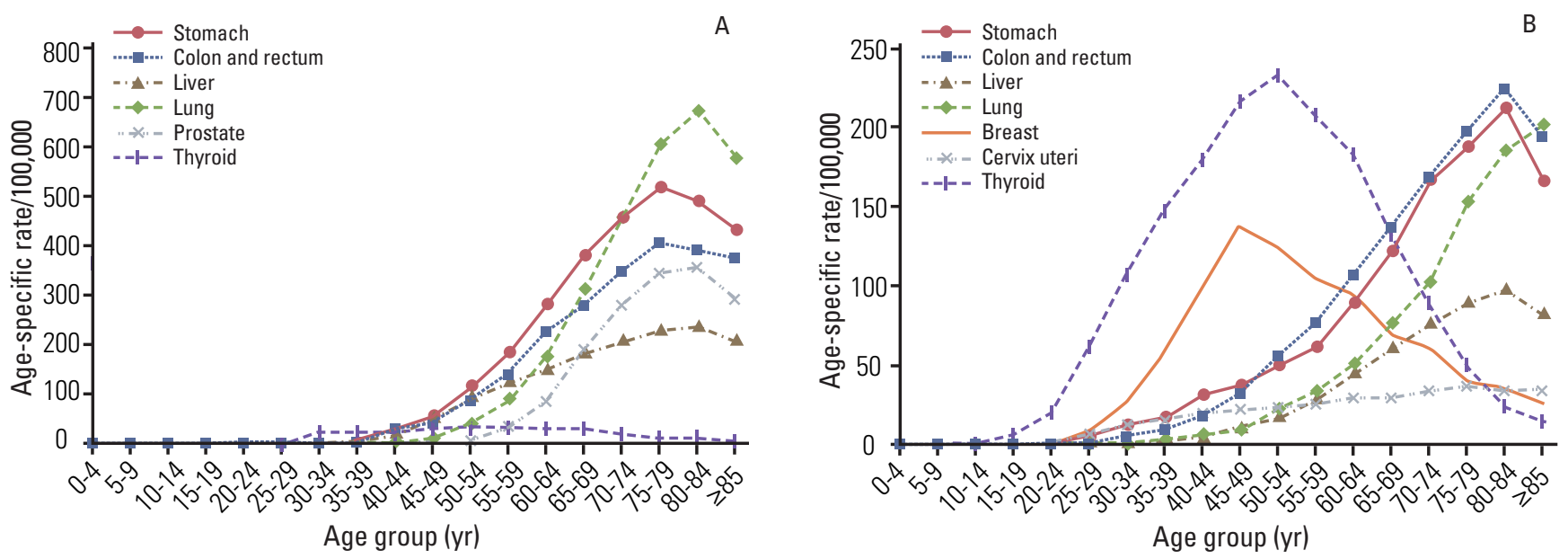

Fig. 3. Age-specific incidence rates for major cancers during 2009 in Korea. (A) Male. (B) Female.
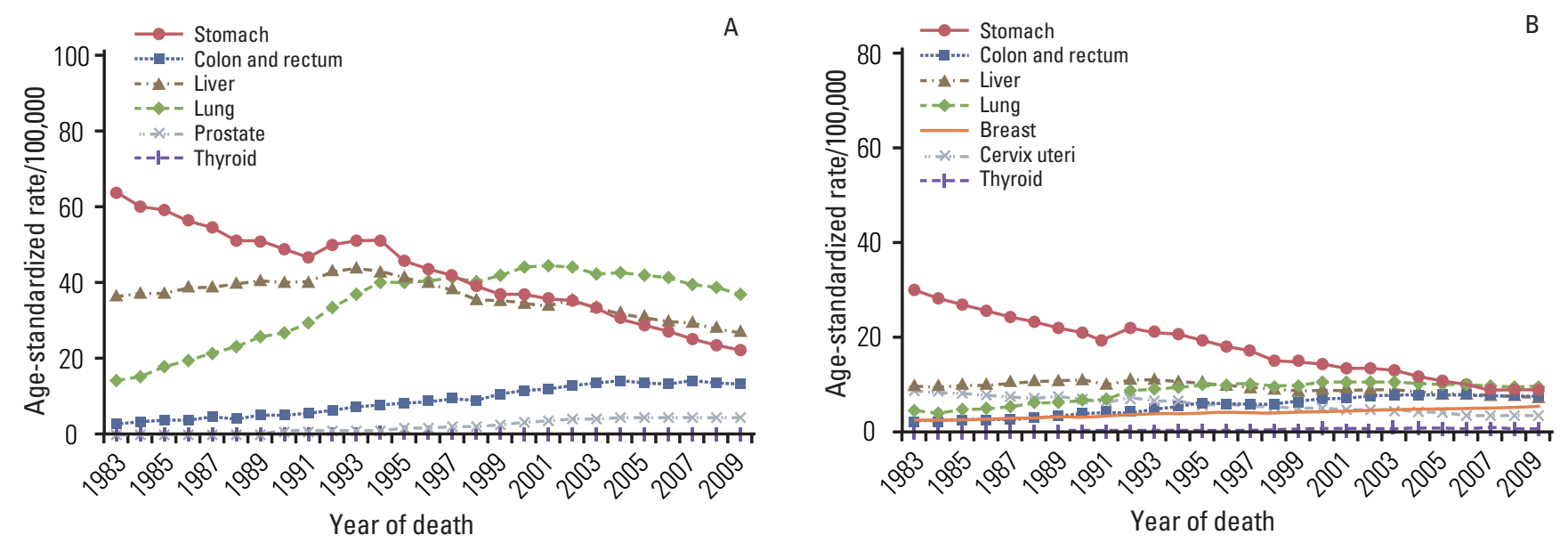

Fig. 4. Annual age-standardized cancer mortality for selected cancers by gender during 1983-2009 in Korea. Age standardization was based on the World Health Organization world standard population. (A) Male. (B) Female. 
more frequent for patients aged $\geq 65$ years. Thyroid cancer was the most common site for middle-aged Korean women (range, 35 to 64 years), and colorectal cancer was the most common among older women (range, $\geq$ 65 years).

Fig. 3 shows the age-specific incidence rates for selected cancers in males and females in 2009. The data show that the incidence of stomach, lung, liver, and colorectal cancers increased gradually with age. Incidence rates for breast and thyroid cancers in females were highest in women in their late $40 \mathrm{~s}$ and early 50s, respectively, and leveled off thereafter. This pattern was very different from rates in Western countries [15].

\section{Trends in cancer mortality}

Figs. 1 and 4 show the trends in cancer deaths for all sites combined and for selected cancer sites. ASRs of mortality have decreased for all sites combined in both sexes since 2002. Lung cancer surpassed stomach cancer as the leading cause of cancer deaths in 1999 and is expected to account for $21.4 \%$ of all cancer deaths in 2009 . The ASRs of mortality due to lung cancer have decreased slightly for men since 2001, but have increased in women. The ASRs of mortality due to stomach and cervical cancers have decreased continuously. The mortality rates of these cancers have also continued to increase along with the significant increases in colorectal, prostate, and female breast cancer incidence.

\section{Survival rates}

Table 9 shows the 5 -year relative survivals for four periods of diagnosis: 1993-1995, 1996-2000, 2001-2005, and 2005-2009. Patients with cancer who were diagnosed in the recent period (2005-2009) had 5-year relative survival rates of $62.0 \%$ for all sites combined in both sexes $(53.2 \%$ in males and $71.4 \%$ in females). When compared with earlier periods, notable improvements were observed in the 5-year relative survival rates for all sites combined. The observation of higher cancer survival rates in females than in males may be partly explained by common cancers in females (e.g., thyroid, breast, and uterine/cervical) that are known to have relatively good prognoses.

When examined by the year of diagnosis and cancer site, the 5-year relative survival rates appeared to be higher for most major cancer sites in patients diagnosed during 2005-2009 compared with 1993-1995, except for pancreatic cancer. The greatest improvements were seen in nonHodgkin lymphoma, prostate, and stomach cancers, as well as leukemia. The improving survival rates could be attributable to early detection and improved treatments [16,17], but this requires further evaluation. A lack of progress in early detection and treatment could explain the observed absence of improvement in the survival rate for pancreatic cancer [18].

Table 8. Five major sites of cancer incidence by age group and gender during 2009 in Korea

\begin{tabular}{|c|c|c|c|c|}
\hline \multirow{2}{*}{ Rank } & \multicolumn{4}{|c|}{ Age group (yr) } \\
\hline & $0-14$ & $15-34$ & $35-64$ & $\geq 65$ \\
\hline \multicolumn{5}{|l|}{ Male } \\
\hline 1 & $\begin{array}{l}\text { Leukemia } \\
\qquad(5.0)\end{array}$ & $\begin{array}{l}\text { Thyroid } \\
(9.4)\end{array}$ & $\begin{array}{c}\text { Stomach } \\
(95.8)\end{array}$ & $\begin{array}{l}\text { Lung } \\
(451.5)\end{array}$ \\
\hline 2 & $\begin{array}{c}\text { Brain and CNS } \\
\text { (2.4) }\end{array}$ & $\begin{array}{l}\text { Stomach } \\
(3.1)\end{array}$ & $\begin{array}{c}\text { Colon and rectum } \\
\text { (71.1) }\end{array}$ & $\begin{array}{l}\text { Stomach } \\
(443.9)\end{array}$ \\
\hline 3 & $\begin{array}{c}\text { Non-Hodgkin lymphoma } \\
\text { (1.6) }\end{array}$ & $\begin{array}{l}\text { Leukemia } \\
\quad(3.0)\end{array}$ & $\begin{array}{l}\text { Liver } \\
(68.1)\end{array}$ & $\begin{array}{c}\text { Colon and rectum } \\
\text { (340.7) }\end{array}$ \\
\hline 4 & $\begin{array}{l}\text { Kidney } \\
(0.5)\end{array}$ & $\begin{array}{c}\text { Colon and rectum } \\
(2.7)\end{array}$ & $\begin{array}{l}\text { Lung } \\
(41.8)\end{array}$ & $\begin{array}{l}\text { Prostate } \\
(268.2)\end{array}$ \\
\hline 5 & $\begin{array}{l}\text { Testis } \\
(0.4)\end{array}$ & $\begin{array}{c}\text { Non-Hodgkin lymphoma } \\
\text { (2.6) }\end{array}$ & $\begin{array}{c}\text { Thyroid } \\
(35.9)\end{array}$ & $\begin{array}{l}\text { Liver } \\
(209.2)\end{array}$ \\
\hline \multicolumn{5}{|c|}{ Female } \\
\hline 1 & $\begin{array}{l}\text { Leukemia } \\
\qquad(3.5)\end{array}$ & $\begin{array}{l}\text { Thyroid } \\
(52.1)\end{array}$ & $\begin{array}{l}\text { Thyroid } \\
(192.5)\end{array}$ & $\begin{array}{c}\text { Colon and rectum } \\
\text { (171.0) }\end{array}$ \\
\hline 2 & $\begin{array}{c}\text { Brain and CNS } \\
\text { (1.7) }\end{array}$ & $\begin{array}{l}\text { Breast } \\
(10.0)\end{array}$ & $\begin{array}{l}\text { Breast } \\
(102.8)\end{array}$ & $\begin{array}{l}\text { Stomach } \\
(160.5)\end{array}$ \\
\hline 3 & $\begin{array}{c}\text { Non-Hodgkin lymphoma } \\
\text { (1.1) }\end{array}$ & $\begin{array}{l}\text { Cervix uteri } \\
\quad(5.3)\end{array}$ & $\begin{array}{c}\text { Stomach } \\
(42.2)\end{array}$ & $\begin{array}{l}\text { Lung } \\
(120.5)\end{array}$ \\
\hline 4 & $\begin{array}{l}\text { Ovary } \\
(0.8)\end{array}$ & $\begin{array}{l}\text { Stomach } \\
(4.2)\end{array}$ & $\begin{array}{c}\text { Colon and rectum } \\
\text { (41.6) }\end{array}$ & $\begin{array}{c}\text { Thyroid } \\
(82.1)\end{array}$ \\
\hline 5 & $\begin{array}{l}\text { Kidney, thyroid } \\
(0.3),(0.3)\end{array}$ & $\begin{array}{c}\text { Colon and rectum } \\
\text { (2.6) }\end{array}$ & $\begin{array}{l}\text { Cervix uteri } \\
\quad(22.0)\end{array}$ & $\begin{array}{l}\text { Liver } \\
(76.9)\end{array}$ \\
\hline
\end{tabular}

CNS, central nervous system. 


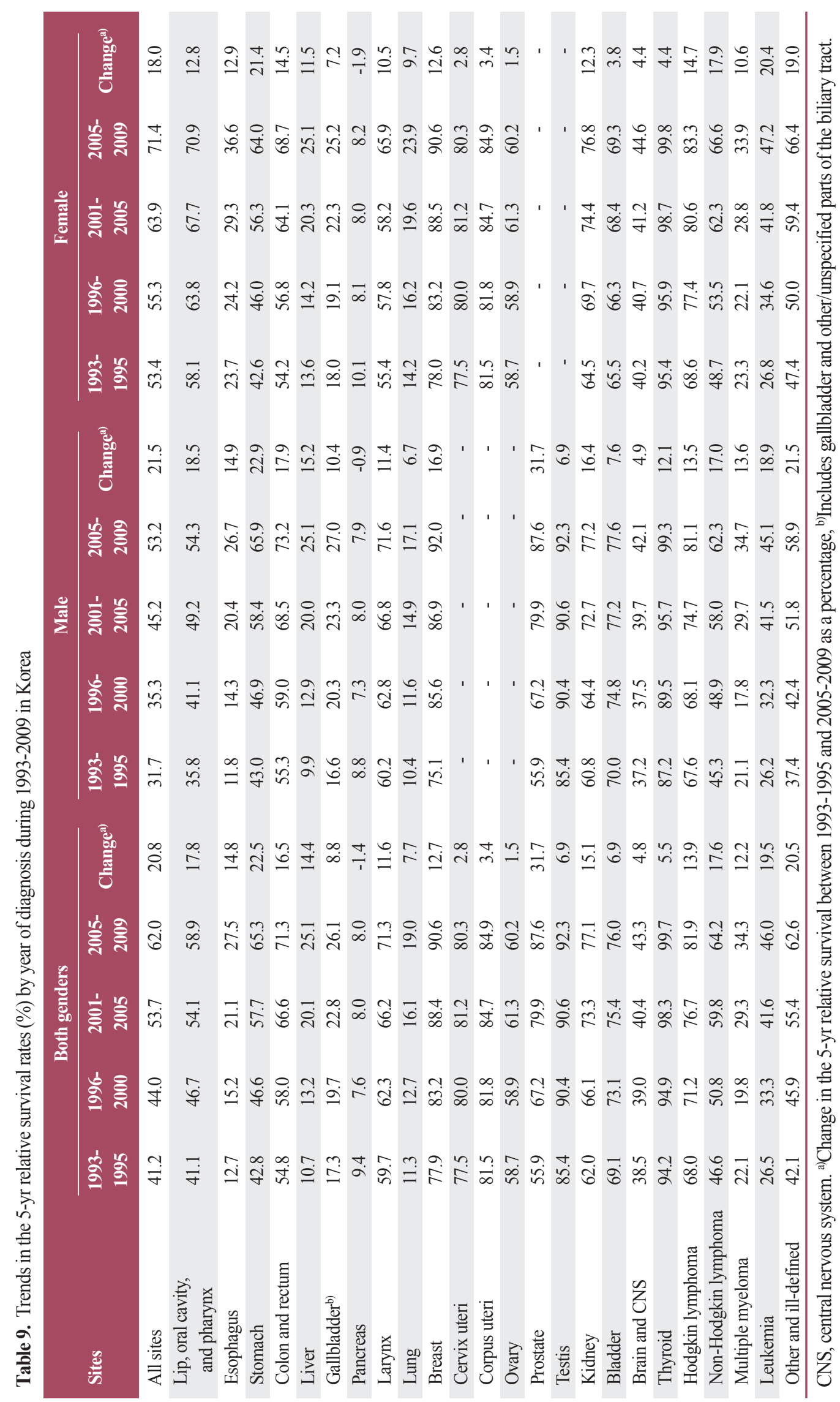




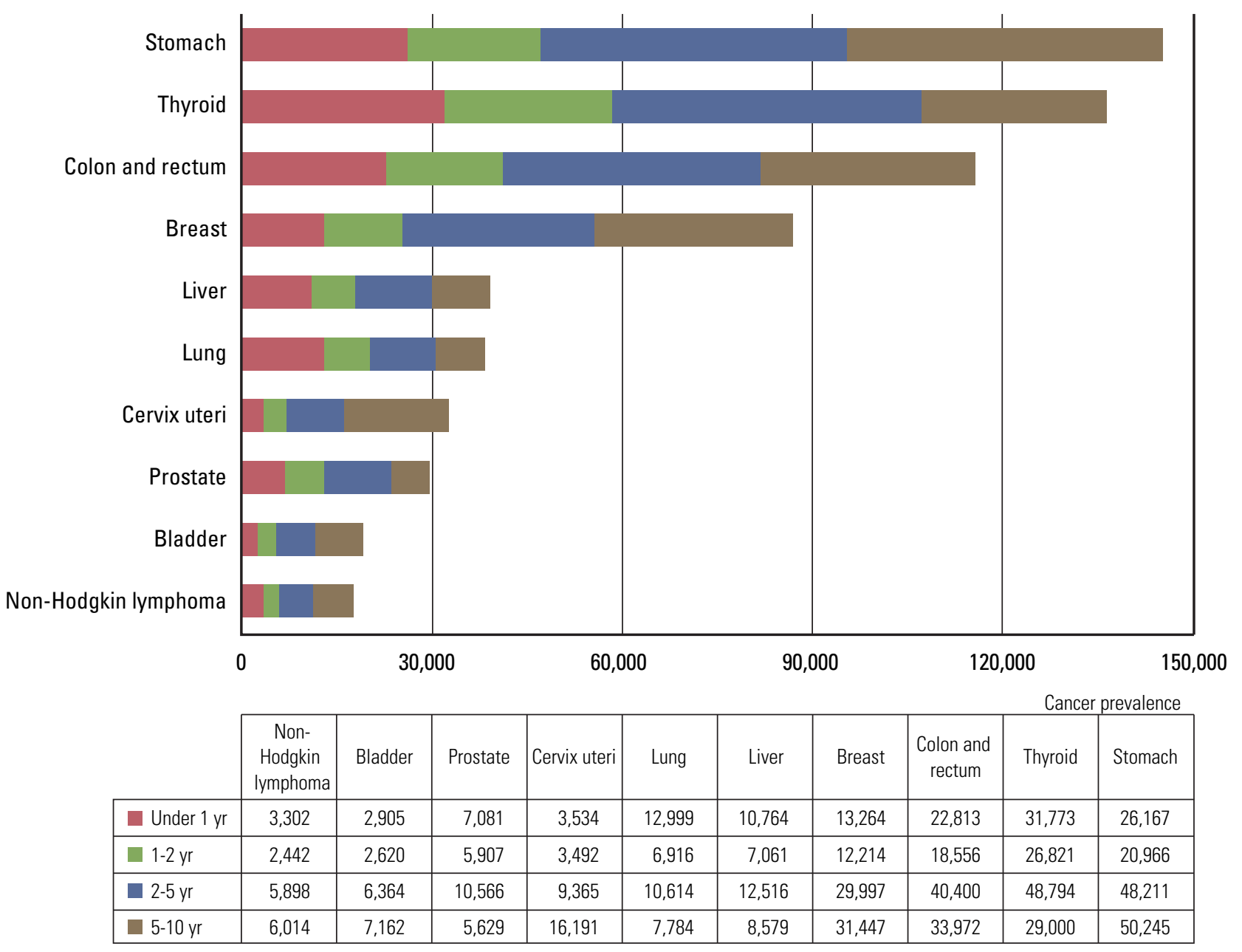

Fig. 5. Number of prevalent cases by time since diagnosis for major cancer sites on January 1, 2010 in Korea.

\section{Prevalence rates}

Table 10 shows the 10-year cancer prevalent rates on January 1,2010 in Korea by sex and cancer site. The 10-year cancer prevalence CRs of all sites combined were 1,491.4 and 1,765.5 per 100,000 in males and females, respectively, and the 10-year cancer prevalence ASRs of all sites combined were 1,218.2 and 1,237.3 per 100,000 in males and females, respectively. In males, the five leading primary sites of cancer for prevalence were the stomach (CR, 389.6; ASR, 312.9), colon and rectum (CR, 275.6; ASR, 223.8), liver (CR, 117.9; ASR, 93.8), prostate (CR, 117.3; ASR, 99.2), and lung (CR, 102.8; ASR, 84.5), accounting for $67.3 \%$ of all cancer prevalent cases. In females, the most common cancer sites were the thyroid (CR, 470.4; ASR, 342.6), breast (CR, 349.2; ASR, 247.0), stomach (CR, 196.4; ASR, 128.5), colon and rectum (CR, 190.4; ASR, 123.4), cervix (CR, 131.5; ASR, 91.0), and lung (CR, 51.4; ASR, 33.3), accounting for $78.6 \%$ of all cancer prevalent cases.

Fig. 5 shows prevalence by time since diagnosis. For all cancers combined, the 1-2-year prevalence represented $36 \%$ of the total prevalent cases. The 1-2-year prevalence as a percentage of the total was highest for thyroid cancer $(20 \%)$, followed by stomach $(16 \%)$ and colorectal (14\%) cancers, which had the high incidence rates and good prognoses. For all cancers combined, the 2- to 5-year and 5- to 10-year prevalence constituted $34 \%$ and $30 \%$ of the total prevalence in both sexes, respectively. The long-term prevalence of lung and liver cancers was relatively low due to lower survival rates.

\section{Conflicts of Interest}

Conflict of interest relevant to this article was not reported. 
Table 10. Crude and age-standardized rates of 10-yr cancer prevalence on January 1, 2010 by gender during 2009 in Korea

\begin{tabular}{|c|c|c|c|c|c|c|}
\hline \multirow{2}{*}{ Sites } & \multicolumn{3}{|c|}{ Crude 10 -yr prevalent rates $/ 100,000$} & \multicolumn{3}{|c|}{ Age-standardized 10 -yr prevalent rates $/ 100,000^{\mathrm{a}}$} \\
\hline & Both genders & Male & Female & Both genders & Male & Female \\
\hline All sites & $1,628.2$ & $1,491.4$ & $1,765.5$ & $1,193.2$ & $1,218.2$ & $1,237.3$ \\
\hline Lip, oral cavity, and pharynx & 24.1 & 33.0 & 15.2 & 17.9 & 26.4 & 10.7 \\
\hline Esophagus & 11.2 & 20.3 & 2.1 & 8.1 & 16.8 & 1.3 \\
\hline Stomach & 293.2 & 389.6 & 196.4 & 211.1 & 312.9 & 128.5 \\
\hline Colon and rectum & 233.1 & 275.6 & 190.4 & 167.4 & 223.8 & 123.4 \\
\hline Liver & 78.4 & 117.9 & 38.7 & 58.2 & 93.8 & 26.7 \\
\hline Gallbladder ${ }^{\text {b) }}$ & 21.7 & 22.2 & 21.3 & 15.4 & 18.2 & 13.3 \\
\hline Pancreas & 10.2 & 11.2 & 9.3 & 7.4 & 9.1 & 6.0 \\
\hline Larynx & 13.4 & 25.1 & 1.6 & 9.7 & 20.7 & 1.0 \\
\hline Lung & 77.2 & 102.8 & 51.4 & 55.5 & 84.5 & 33.3 \\
\hline Breast & 175.0 & 1.6 & 349.2 & 125.9 & 1.3 & 247.0 \\
\hline Cervix uteri & 65.6 & - & 131.5 & 47.0 & - & 91.0 \\
\hline Corpus uteri & 20.1 & - & 40.3 & 14.9 & - & 29.1 \\
\hline Ovary & 20.2 & - & 40.5 & 15.5 & - & 30.5 \\
\hline Prostate & 58.8 & 117.3 & - & 40.2 & 99.2 & - \\
\hline Testis & 3.0 & 5.9 & - & 2.8 & 5.4 & - \\
\hline Kidney & 34.3 & 46.1 & 22.4 & 25.7 & 36.8 & 16.1 \\
\hline Bladder & 38.4 & 62.3 & 14.4 & 26.8 & 51.5 & 8.6 \\
\hline Brain and CNS & 13.1 & 13.8 & 12.4 & 11.8 & 12.7 & 10.9 \\
\hline Thyroid & 274.7 & 79.7 & 470.4 & 201.7 & 59.6 & 342.6 \\
\hline Hodgkin lymphoma & 2.7 & 3.5 & 2.0 & 2.4 & 3.0 & 1.8 \\
\hline Non-Hodgkin lymphoma & 35.6 & 39.0 & 32.1 & 27.8 & 32.5 & 23.8 \\
\hline Multiple myeloma & 5.5 & 5.8 & 5.2 & 4.0 & 4.7 & 3.5 \\
\hline Leukemia & 21.3 & 23.4 & 19.1 & 21.0 & 23.4 & 18.7 \\
\hline Other and ill-defined & 97.6 & 95.4 & 99.8 & 75.0 & 82.1 & 69.4 \\
\hline
\end{tabular}

CNS, central nervous system. a)Age adjusted to the World Health Organization world standard population, ${ }^{\text {b) }}$ Includes gallbladder and other/unspecified parts of the biliary tract.

\section{Acknowledgments}

This work was supported by a research grant from the National Cancer Center (No. 1010160) and National Health Promotion Program grants (Nos. 1160390 and 1160400) from the Ministry of Health and Welfare,
Republic of Korea. The authors are indebted to the Korea Central Cancer Registry (KCCR)-affiliated hospitals, non-KCCR-affiliated hospitals, 11 regional cancer registries (Busan, Daegu \& Gyeongbuk, Gwangju \& Jeonnam, Incheon, Daejeon \& Chungnam, Ulsan, Gangwon, Chungbuk, Jeonbuk, Gyeongnam, and Jejudo), the National Health Insurance Corporation, and Statistics Korea for data collection.

\section{References}

1. Statistics Korea, 2011 [Internet]. Daejeon: Statistics Korea; 2011 [cited 2012 Jan 16]. Available from: http://kostat.go.kr.

2. Jung KW, Park S, Kong HJ, Won YJ, Lee JY, Park EC, et al. Cancer statistics in Korea: incidence, mortality, survival, and prevalence in 2008. Cancer Res Treat. 2011;43:1-11.

3. Won YJ, Sung J, Jung KW, Kong HJ, Park S, Shin HR, et al. Nationwide cancer incidence in Korea, 2003-2005. Cancer Res Treat. 2009;41:122-31.

4. Shin HR, Won YJ, Jung KW, Kong HJ, Yim SH, Lee JK, et al. Nationwide cancer incidence in Korea, 1999 2001: first result using the national cancer incidence database. Cancer Res Treat. 2005;37:325-31.

5. Ajiki W, Tsukuma H, Oshima A. Index for evaluating completeness of registration in population-based cancer registries and estimation of registration rate at the Osaka Cancer Registry between 1966 and 1992 using this index. Nihon Koshu Eisei Zasshi. 1998;45:1011-7.

6. Fritz A, Percy C, Jack A, Shanmugaratnam K, Sobin L, Parkin DM, et al. International classi- fication of diseases for oncology. 3rd ed. Geneva: World Health Organization; 2000.

7. World Health Organization. Manual of the international statistical classification of diseases, injuries, and causes of death. 10th rev. Geneva: World Health Organization; 1992.

8. Segi M. Cancer mortality for selected sites in 24 countries (1950-1957). Sendai: Tohoku University School of Medicine; 1960.

9. Altekruse SF, Kosary CL, Krapcho M, Neyman N, Aminou R, Waldron W. SEER cancer statistics review, 1975-2007. Bethesda, MD: National Cancer Institute; 2010.

10. National Cancer Institute. SEER*Stat Program, version 6.6.1 [Internet]. Bethsda, MD: National Cancer Institute; 2011 [cited 2011 Jan 14]. Available from: http://seer.cancer.gov/seerstat/.

11. Ederer $F$, Heise $H$. Instructions to IBM programmers in processing survival computations. Methodological note No. 10. Bethesda, MD: National Cancer Institute; 1959.

12. Dickman P [Internet]. Stockholm: PaulDickman.com [cited 2009 Apr 14]. Available from: http//www.pauldickman.com. 
13. Davies L, Welch HG. Increasing incidence of thyroid cancer in the United States, 1973-2002. JAMA. 2006;295:2164-7.

14. Enewold L, Zhu K, Ron E, Marrogi AJ, Stojadinovic A, Peoples GE, et al. Rising thyroid cancer incidence in the United States by demographic and tumor characteristics, 1980-2005. Cancer Epidemiol Biomarkers Prev. 2009;18:784-91.

15. Curado MP, Edwards B, Shin HR, Stom H, Ferlay J, Heanue M. Cancer incidence in five continents, vol. 9. Lyon: IARC; 2007.
16. Jung KW, Yim SH, Kong HJ, Hwang SY, Won YJ, Lee JK, et al. Cancer survival in Korea 1993-2002: a population-based study. J Korean Med Sci. 2007;22 Suppl:S5-10.

17. Gondos A, Bray F, Hakulinen T, Brenner H; EUNICE Survival Working Group. Trends in cancer survival in 11 European populations from 1990 to 2009: a model-based analysis. Ann Oncol. 2009;20:564-73.

18. Dickman PW, Adami HO. Interpreting trends in cancer patient survival. J Intern Med. 2006;260:103-17. 